\title{
La herencia alfarera en la península de Nicoya: Persistencia de una tradición
}

\author{
Jim Weil $^{1}$ y Anayensy Herrera ${ }^{2}$
}

${ }^{1}$ Science Museum of Minnesota, Estados Unidos; jimweilanthro@gmail.com

${ }^{2}$ Centro Científico Tropical, Costa Rica; anayensyherrera@gmail.com

Resumen: La documentación de la manufactura de tres tipos de piezas cerámicas en San Vicente de Nicoya posibilita inferencias en cuanto a las continuidades y los cambios en las materias primas, las herramientas, las técnicas, la organización del trabajo, los estilos y los usos. Los hallazgos sirven a los propósitos de arqueólogos, historiadores y etnólogos en busca de elementos que revelen tradiciones artesanales antiguas y recientes, que todavía se experimentan en el presente. Tales investigaciones interdisciplinarias contribuyen al rescate y reforzamiento de la herencia cultural local.

Palabras clave: Alfarería, tradiciones artesanales, etnoarqueología, etnohistoria, Costa Rica.

The ceramic heritage on the Nicoya Peninsula: Persistence of a tradition

Abstract: Documentation of the manufacture of three types of ceramic pieces in San Vicente de Nicoya supports inferences about continuities and changes in raw materials, tools, techniques, organization of work, styles and uses. The findings serve the purposes of archaeologists, historians and ethnologists looking for elements of ancient and more recent artisan traditions which still are practiced in the present. Such interdisciplinary research contributes to the preservation and reinforcement of the local cultural heritage. Keywords: Ceramic artisan traditions, ethnoarchaeology, ethnohistory, Costa Rica.

Cuadernos de Antropología 2014, 24(2), 25-47

Recibido: 19-11-2013 / Aceptado: 25-10-2014

Revista del Laboratorio de Etnología María Eugenia Bozzoli Vargas Escuela de Antropología, Universidad de Costa Rica

http://revistas.ucr.ac.cr/index.php/antropologia

ISSN 2215-356X 


\section{Introducción}

La alfarería de San Vicente de Nicoya y Guaitil de Santa Cruz, caseríos vecinos en la península de Costa Rica, ha recibido una amplia atención por parte de investigadores académicos y periodistas de los medios de comunicación. Sin embargo, son escasos los trabajos investigativos que profundicen sobre esta extensa y particular tradición. A pesar de que la alfarería se ha difundido a todas las regiones de Costa Rica y a un buen número de países a lo largo del mundo, poca gente conoce sobre la historia de los estilos que representa, y aún menos sobre la herencia que incorpora sus técnicas, sus usos y significados.

El presente estudio estará dirigido a destacar varios aspectos relacionados con la cultura material asociada a la tradición alfarera, pero a la vez considerará aspectos inmateriales o intangibles. Para ello se describirán las etapas detalladas de la manufactura de tres piezas cerámicas: un comal, una tinaja y la réplica de una pieza precolombina local. A partir de la observación del proceso de confección, así como con los datos complementarios de investigaciones arqueológicas, históricas y etnográficas, se propondrán elementos de continuidad y cambio en esta industria tradicional. Se espera que los resultados de este estudio contribuyan en los procesos de rescate y reforzamiento de la identidad cultural a nivel local, regional y nacional.

El artículo está organizado de la siguiente manera. Hay dos secciones iniciales que tratan sobre el marco teórico de la investigación y su contexto geográfico e histórico. Ellas son importantes para indicar que las actividades encontradas en el presente representan la culminación de un conjunto de acontecimientos acumulados a lo largo de cientos de años, en cuanto a los orígenes de las prácticas y a los propósitos de la alfarería. Señalan, a la vez, una metodología interdisciplinaria que nos permite reconocer cuándo, por qué y cómo aparecieron las innovaciones, pero también lo que se perdió de la tradición acumulativa.

La tercera sección contiene una descripción de los detalles de la manufactura. Las tres piezas representan tipos seleccionados para distinguir elementos clave del pasado y que todavía se encuentran en la actualidad. Una muestra de ilustraciones ayuda en la visualización del proceso.

La cuarta sección resalta la continuidad de pautas relevantes e identifica cambios significativos, ya sea en los materiales, herramientas y técnicas del proceso, organización social, usos y en los estilos de los productos. De esta manera, se demuestra el potencial de aprender permanentemente de la historia cultural, de entender mejor el porqué de las prácticas y su persistencia. De esta forma, se concluye con una discusión sobre los retos de las investigaciones actuales y futuras.

http://revistas.ucr.ac.cr/index.php/antropologia 


\section{Marco teórico}

Para analizar la trayectoria histórica de esta tradición, se proponen tres etapas. Estas definen lapsos de tiempo específicos a los que es posible abordar desde diferentes fuentes de información, dada la aproximación metodológica que realizan distintas disciplinas:

- Etapa antigua: empieza con los primeros indicios de alfarería en esta región geográfica que se remontan al segundo milenio antes de nuestra era; atraviesa la historia de los pueblos de origen chibchense hasta la época de las mayores interacciones con Mesoamérica, lo que dio origen al nombre de la Gran Nicoya (pacífico de Nicaragua y el noroeste de Costa Rica) y continúa con la exploración y colonización española a lo largo del siglo XVI. La fuente principal de información es la arqueología que estudia los restos de cultura material.

- Etapa histórica intermedia: asociada con la vida cotidiana en las poblaciones campesinas y que involucra utensilios domésticos que poseen muy pocos o ningún detalle decorativo; empieza en el período de la colonia española y se extiende hasta mediados del siglo XX. La información proviene de reportes realizados por estudios durante la primera mitad del siglo XX, así como de los recuerdos de la niñez y juventud de los artesanos mayores en el trabajo cotidiano de sus hogares.

- Etapa reciente: empezó en la década del 60 del siglo XX, cuando el surgimiento del turismo global promovió un renacer de formas y estilos precolombinos, llamados por los artesanos como motivos chorotegas, junto con innovaciones más recientes denominadas motivos ecológicos. La información disponible deriva de las observaciones etnográficas de los procesos de manufactura, intercambio y uso; es la evidencia que se ve materializada en las piezas terminadas y en los comentarios por parte de los artesanos acerca de su trabajo actual.

Cada una de estas etapas produce diferentes tipos de hallazgos que contribuyen a una comprensión amplia e integrada para comprender cómo la tradición alfarera de la Península de Nicoya ha transmutado a través del tiempo

Para cualquier actividad particular que se observe en la actualidad, y especialmente en una industria artesanal con una tradición tan extensa como esta, una pregunta clave es cuándo se puede datar su origen en el pasado. El propósito es precisamente diferenciar los rasgos de origen precolombino de aquellos que 
surgieron en otras épocas y buscar así una explicación, tanto de las continuidades como de las discontinuidades. Para entender mejor las fuerzas sociales involucradas, así como los cambios en el corto y largo plazo implicados, se ofrecen dos perspectivas: la primera a nivel macro, la segunda es micro.

Desde un punto de vista macro, las tres etapas pueden ser concebidas como ondas secuenciales del tipo que dejan las piedras al caer en un charco. El impacto cultural de la conquista española y del establecimiento de una sociedad campesina, generó ondas que cubrieron rasgos entonces existentes o los empujaron a los márgenes. La modernización surgida a mediados del siglo XX, constituyó otra onda que desplazó los utensilios de cocina elaborados en barro por objetos industrializados de metal, vidrio y plástico. Sin embargo, subsistió cierta alfarería tradicional precedente, incluso después que el mercado de objetos domésticos utilitarios fuera eclipsado por el mercado de arte y souvenirs étnicos. Al mismo tiempo, los pasos del proceso de manufactura siguieron siendo esencialmente los mismos. Tomando prestado el vocabulario de la biología evolucionista: la ontología de una pieza recapitula la filogenia de la tradición.

En un punto de vista micro, los cambios surgen de las modificaciones, a menudo mínimas, en las prácticas cotidianas de los artesanos. Hay una serie de ciclos, empezando con las repeticiones casi idénticas de las etapas de manufactura, cada vez que se realiza cierto tipo de pieza. También hay ciclos anuales en que los artesanos repiten los procedimientos de manufactura y almacenaje de piezas, los que durante los períodos de mayor turismo involucran la movilización de grupos de trabajadores. Los ciclos vitales también generan ciclos de aprendizaje inicial, así como el refinamiento de las destrezas manuales fundamentales y, en el caso de algunos artesanos, de destrezas manuales más complejas. Las innovaciones teóricas y metodológicas recientes en la arqueología, así como en la etnografía, tratan sobre la relación entre la estructura (las restricciones y oportunidades circunstanciales) y la voluntad (agency o la elección individual) en los procesos de cambio social (Dobres, 1999; Ortner, 2006). Estas son pertinentes para el presente estudio de caso centrado en las decisiones que toman los artesanos.

Una manera de observar los ciclos de corta y larga duración es haciéndolo de manera conservadora, manteniendo y perpetuando la tradición general. La perspectiva opuesta destaca las modificaciones que a veces suceden de un ciclo a otro, ya sean mínimas, y tal vez hasta sin importancia, o mayores -por ejemplo, en una herramienta, en una técnica, o un detalle estilístico- y todos generalmente con un efecto duradero. Los ciclos pueden ser vistos entonces como círculos cerrados, cuando no ha ocurrido ningún cambio significativo, y como espirales abiertas, cuando algo nuevo ha aparecido en los ciclos subsiguientes (cf. Gould, 1988). Los principos que subyacen en los procesos de cambio social podrían ser discutidos de manera más exhaustiva, pero estos comentarios deberían ser suficientes como marco para una comprensión preliminar de las fuentes, así como de las consecuencias de las prácticas y los resultados específicos que se tratarán a continuación. 


\section{Contexto geográfico-histórico}

Cada comunidad, y por lo tanto cada estudio etnográfico, es única por su ubicación espacial y temporal. Las comunidades contiguas de San Vicente y Guaitil, como el resto de Costa Rica en la actualidad, comparten una historia cultural regional que se inicia con la interrelación de los pueblos chibchenses, en una vasta región que comprende el sur del itsmo de América Central y el noroeste de América del Sur. Hace alrededor de 1200 años, durante el epiclásico de Mesoamérica, varios grupos procedentes de México emigraron hacia el sur y se establecieron en parte de los territorios de la actual Nicaragua y Costa Rica; hoy se reconocen como chorotegas y nicaraos (Constenla, 1994). San Vicente y Guaitil se encuentran dentro de esta subárea arqueológica Gran Nicoya (Lange, 1984). El ligamen con una tradición cultural mesoamericana persiste, no solamente en la industria alfarera actual, sino también en lo que tiene que ver con la dieta basada en el maiz y en su característica tortilla de tamaño grande y grueso (Herrera, 2004).

El ocaso de las sociedades precolombinas, a raiz de la arremetida de la conquista y colonización española, llevó a su fin la producción de alfarería compleja destinada a representar las creencias religiosas y a los rituales asociados. En 1529, el explorador Gonzalo Fernández de Oviedo afirmó haber visto en la isla de Chira, localizada en el Golfo de Nicoya, un conjunto de utensilios negros finamente elaborados. Hay documentos que datan de 1548 y 1573, de pueblos que ofrecieron su tributo a la corona española a través de alfarería (Abel-Vidor, 1980; Meléndez, 1974; Solórzano y Quirós, 2006). Sin duda, la industria de la alfarería utilitaria continuó a lo largo de esta región, pero existe muy poca evidencia arqueológica o documentos escritos que diluciden los siglos que siguieron.

Los testimonios más tempranos sobre los que tenemos noticias de los artesanos del grupo de comunidades de estudio datan de hace apenas cien años. El autor de estos, el entonces director del Museo Nacional de Costa Rica, Anastasio Alfaro, dejó el relato de su visita a los artesanos del cercano caserío Chira (cuyo nombre coincide con el de la isla en el golfo de Nicoya), ubicado a escasos tres kilómetros de San Vicente. En su exposición anticipó los posibles beneficios económicos de un perfeccionamiento de las técnicas para acercarse a los logros de sus ancestros (Alfaro, 1914). Existe otro testimonio aún más detallado y bien ilustrado de la industria local situado a mediados del siglo XX. Dicho artículo de la arqueóloga y etnógrafa Doris Stone (2010 [1950]) sirve como punto de referencia para cotejar las continuidades y cambios en los materiales, las herramientas, las técnicas, la organización social, las formas y los estilos (traducciones de pasajes seleccionados se encuentran en Weil, 2010). Otro estudio del mismo período hace alusión a la misma industria local, junto con algunas otras, en una descripción más amplia de la vida rural de la península de Nicoya (Wagner, 1974 [1958]). Gracias a estas contribuciones, se cuenta con material para llevar a cabo un análisis comparativo. 
En tanto, ciencia social, la antropología puede sacar conclusiones sobre las causas y los efectos de los cambios, de acuerdo con los principios subyacentes que dirigen la formación de las instituciones humanas. Igualmente, los antropólogos pueden trabajar como científicos conductistas y documentar lo que hacen los individuos, según los principios de percepción, elección y acción, tanto en el presente como en el pasado (Herrera, 2001). De esta manera, una fundamentación empírica de las observaciones sistemáticas puede ubicar la persistencia de la industria alfarera artesanal en San Vicente y Guaitil, como el final de una larga secuencia de acontecimientos, y asociarlos con sucesos de otros lugares.

\section{Un estudio de los procesos de manufactura}

Esta sección está basada en observaciones directas de la manufactura de tres tipos de piezas. La primera es el comal, un elemento fundamental que identifica la dieta mesoamericana a través del consumo de la tortilla y cuya presencia hoy representa siglos de persistencia de esta tradición. Se le emplea para "echar tortillas" que se consumen en hogares rurales, especialmente en el noroeste de Costa Rica. La artesana principal es Maira Grijalba Campos de 59 años (esta edad y las otras abajo corresponden al momento de realizar el estudio), quien empezó a dedicarse al trabajo de alfarería al llegar a la edad adulta (Figura 1A). Junto con su sobrina, Karen Salinas Grijalba, continúa la tradición de su madre, Clara (la abuela de Karen), quien hizo comales y tinajas la mayor parte de su vida. El segundo tipo de pieza es la tinaja, la cual ha perdido su propósito tradicional de recipiente para almacenar el agua. La artesana es Zoraida Grijalba Villafuerte, de 77 años, ella aprendió todo lo que sabe sobre alfarería de su madre y ha transmitido sus destrezas a las nuevas generaciones. Zoraida seguía haciendo hasta muy recientemente tinajas tradicionales, así como también otros tipos de utensilios de cocina, muchos de los cuales están en desuso, pero que mantuvieron su consumo como piezas decorativas nostálgicas (Figura 1B). El tercer tipo es la réplica de una pieza precolombina identificada como del tipo cerámico Jicote Polícromo, presumiblemente parte del conjunto de una alfarería ritual sofisticada en gran parte de Guanacaste durante el período prehispánico tardío. El auge del turismo a partir de fines de los años 60 creó una demanda de mercado que estimuló a algunos artesanos, incluyendo por primera vez a hombres, a redescubrir técnicas para dar forma y hornear estas piezas más complejas de alfarería. La muestra aquí seleccionada fue realizada por Carlos Grijalba Acosta, de 55 años, quien se declaró "encantado" con el reto de hacer réplicas de piezas difíciles (Figura 1C). Este artesano se convirtió en especialista de la alfarería cuando quedó viudo con hijos pequeños, por lo que decidió trabajar en casa. A diferencia de los artesanos que elaboraron las demás piezas, Carlos siempre trabajaba solo.

\section{Maira y Karen hacen comales — la perpetuación de la tradición}

Los comales se hacen de manera más eficiente cuando se realizan en tandas de varias docenas por artesanos que a menudo trabajan en conjunto. Karen empieza el proceso tomando un pedazo de arcilla, dándole forma de pelota sobre una mesa cubierta con arena para que no se adhiera. Luego, aplana la pelota para 


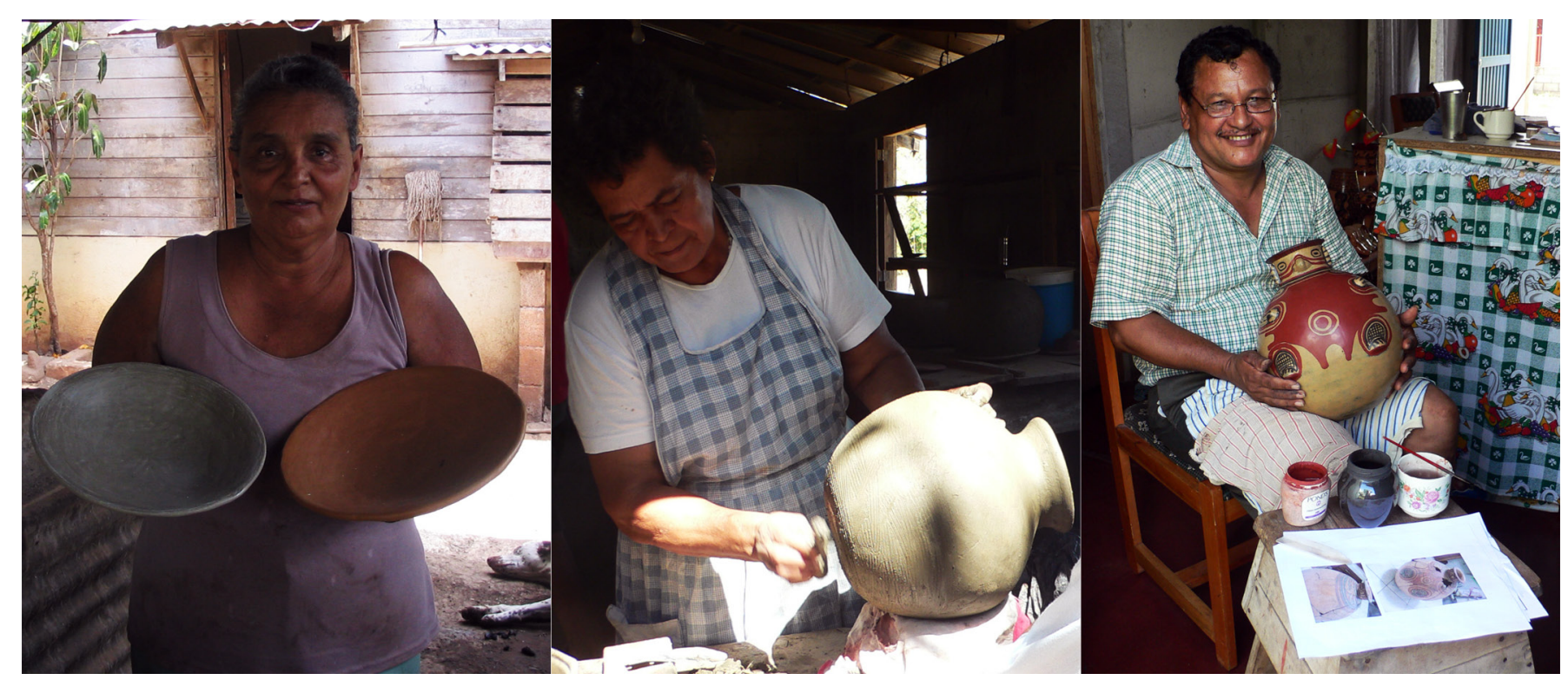

Figura 1: A. Maira Grijalba Campos (Foto J. Weil), B. Zoraida Grijalba Villafuerte (foto de J. Weil), C. Carlos Grijalba Acosta (foto de A. Herrera).

obtener una "tortilla" de arcilla y así repite el proceso hasta tener un montón de piezas de la misma forma circular. Maira trabaja estas piezas una por una, apretando cada una sobre un comal que sirve de molde. Luego, con los dedos les quita el exceso de arcilla. Utiliza agua, una "cuchara" (pedazo de plástico) para emparejar la superficie interior del comal y un pedazo de cuero para suavizarla.

Una vez que tienen muchas piezas en esta etapa del proceso, Karen y Maira empiezan a trabajar las superficies. Maira emplea la hoja de un cuchillo para recortar los bordes y raspar la parte inferior del comal, hasta que queda simétrico y con el grosor adecuado. Saca los guijarros minúsculos y otras impurezas de la arcilla con la punta del cuchillo; agrega más arcilla para remendar los agujeros que pueda haber y frota hasta sacar todas las irregularidades. A su vez, Karen frota una piedra dura y brillante (roca silícea generalmente cuarzo) llamada sukia, en la superficie interior del comal para hacer que quede lisa (Figura 2); esto se hace para que las tortillas no se peguen cuando se estén cocinando. Por esta misma característica, los arqueólogos pueden reconocer que algunos fragmentos cóncavos son comales porque son lisos en la parte interior y rugosos por fuera (Herrera, 2001; 2004). Cuando se termina el proceso de dar forma a los comales, se dejan secar durante uno o dos días.

Cuando está lista una tanda lo suficientemente grande de comales (varias docenas), se introducen en el horno cerrado en forma de colmena. Este tipo de horno fue introducido durante la colonia española, ya que, según los hallazgos arqueológicos, durante la época precolombina se horneaba en hoyos en el suelo (Abel, 1978; Herrera, 2001; Solís, 1996) y posiblemente en cavidades dentro de paredones (Herrera y Weil, 2009). Cuidadosamente, Karen coloca cada comal en la horqueta que sostiene Maira, y esta los ordena con 


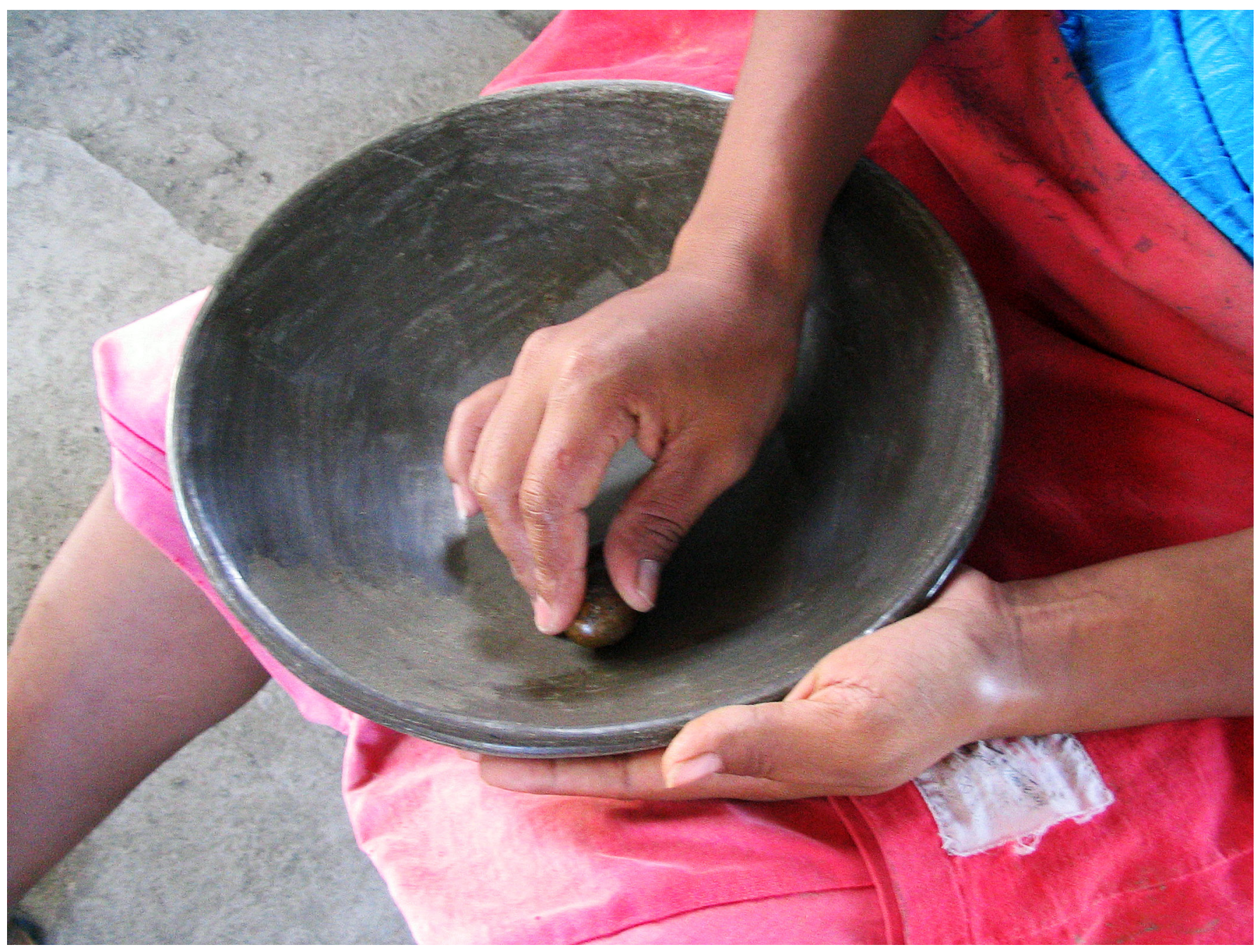

Figura 2: Empleo de la piedra sukia para alujar la superficie del comal (Foto J. Weil).

el máximo cuidado, uno por uno, cerca de los trozos ardientes y brillantes de la madera que arde dentro del horno (Figura 3). Se hornean juntos una docena o más de comales en varias tandas que demandan un proceso de varias horas. Entre tanto, Maira va agregando madera para mantener encendido el fuego. Cuando terminan de hornearse, retira con cuidado los comales colocándolos en el suelo separadamente para que se enfríen. Un comal debe ser bien horneado para que la pieza sea duradera.

Cuando se han enfriado los comales, Karen los divide en tres grupos: uno para sí misma, otro para Maira, y el tercero para la hija de Maira (para sufragar sus gastos de colegio). La mayoría de los comales son adquiridos por comerciantes mayoristas, luego son comercializados en puntos de venta al por menor, y finalmente, son utilizados en hogares de toda la región para cocinar las tradicionales tortillas. 


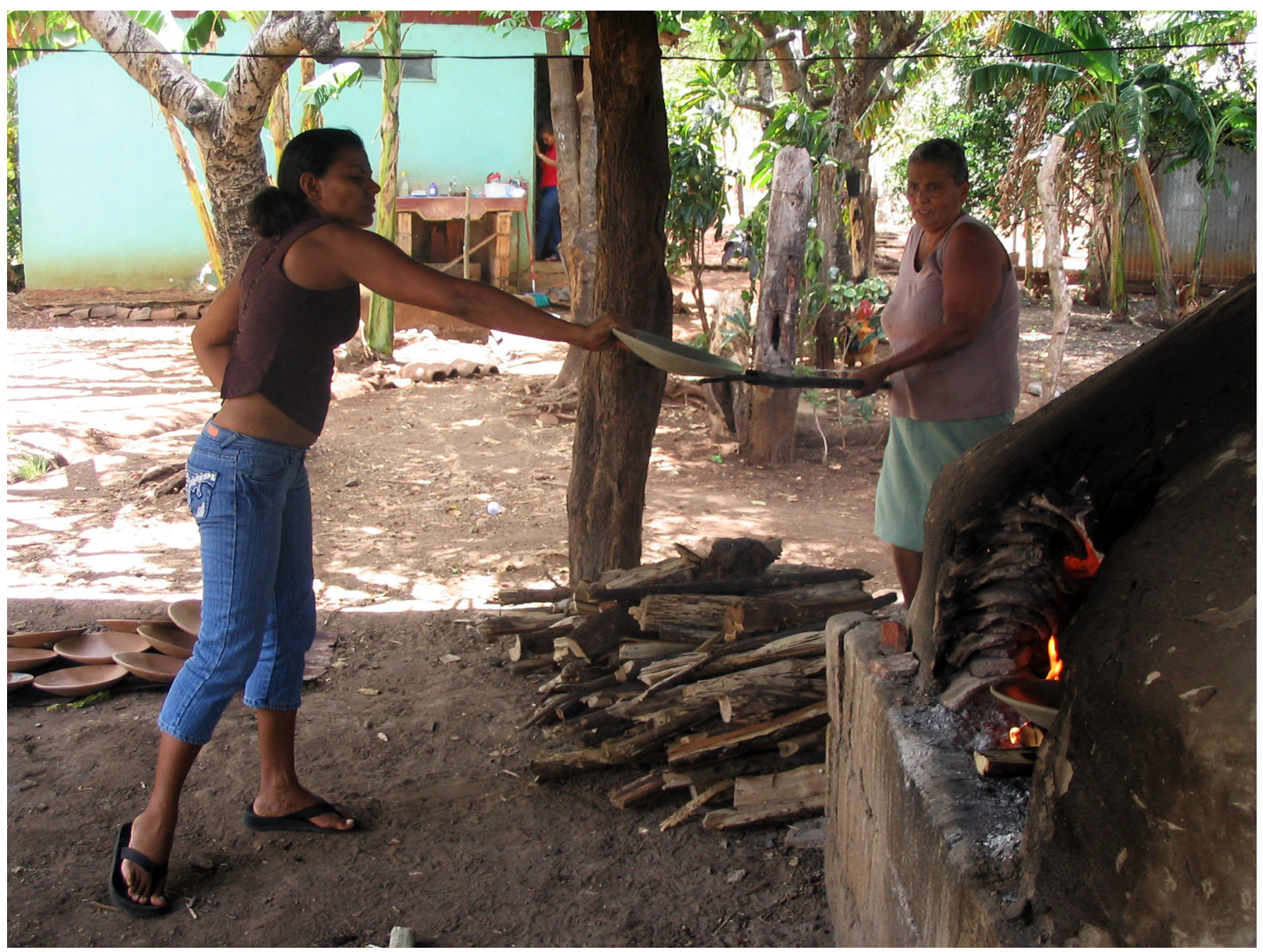

Figura 3: Karen y Maira colocando los comales en el horno para su cocción (Foto J. Weil).

\section{Zoraida hace una tinaja — la resistencia al declive de la tradición}

Hasta mediados del siglo XX se utilizaban vasijas esféricas con cuellos angostos para almacenar el agua para consumo humano. Hoy todavía se elaboran como piezas decorativas en tamaño estándar con una mayor variedad de elementos ornamentales, pero también en versiones más grandes y otras más pequeñas. Zoraida comienza haciendo la parte inferior del recipiente con un trozo grande de arcilla, formando un disco por medio de golpes y palmadas. Luego lo coloca en el molde que sirve de base, generalmente es un comal encima de un rol (ver más adelante) que hace girar manualmente. Al comenzar a formar la parte inferior de la vasija, Zoraida lleva la arcilla hacia arriba y la raspa horizontalmente con los dedos, para darle al recipiente la conformación básica. Luego forma y coloca el primer rollo, una pieza larga similar a un 
chorizo que se coloca en el borde superior, seguido de otra pieza más corta para abarcar el resto del borde. Utiliza sus manos para unir el rollo, aplanando y emparejando la arcilla, formando así toda la extensión del borde (Figura 4). Luego, Zoraida levanta y afina la pared del recipiente. Raspa la superficie exterior con un olote (o corazón de la mazorca de maíz), que también elimina las irregularidades de la textura de la pared de la vasija. Para la parte interior, utiliza una cuchara o pedazo de jícara (calabaza), pero explica que hoy se puede utilizar una herramienta similar hecha con plástico. Al finalizar esta etapa, la pieza está semiterminada, pero debe dejársela reposar hasta que se endurezca la arcilla; de otro modo, el siguiente rollo, por su peso, la haría deformarse.

Después de que se seca - esto es al cabo de alrededor de media hora-, la pieza se vuelve más firme (con la contextura del cuero) y se puede retomar el trabajo. Zoraida agrega otros rollos, uno encima del otro, para seguir armando la vasija. Utiliza los dedos para apretar y presionar hacia abajo los rollos alrededor de todo el borde. Seguidamente, Zoraida arma y pega otro rollo más pequeño y chato llamado el gollete (cuello). Son elementos característicos de las tinajas, la forma esférica casi perfecta y el gollete que se ensancha hacia afuera. Para terminar el borde, Zoraida coloca abundante agua y recorre el olote alrededor de toda la tinaja para emparejar la superficie. Con una hoja de guayaba húmeda (Psidium guajava) recorre el borde hasta dejarlo muy suave. Para pulir la superficie, lo frota con una piedra sukia para producir una textura compacta y lisa ("asentar").

La pintura decorativa es el último paso importante antes de colocar las piezas en el horno. La zona aledaña a San Vicente y Guaitil posee las únicas fuentes conocidas de pigmento mineral de color beige y rojo, llamado curiol (ver más adelante). Se hacen polvo los nódulos de color y se diluyen con agua. Lo primero es colocar el curiol en una textura cremosa sobre toda la pieza, esto se denomina técnicamente como colocar el engobe. Esta operación se hace mientras la tinaja está todavía húmeda. Lo segundo es esperar que se seque para pulir y, finalmente, pintar los diferentes diseños encima del engobe. Uno de los motivos de la Gran Nicoya que le gusta incorporar a Zoraida es el diseño formado por una línea continua que va formando distintos colochos y cuyo resultado deriva en varias formas. Utiliza una cuchara de plástico (en este caso no es de calabaza), luego de que cada capa de curiol es aplicada -incluso a la pintura decorativa- para fundirlas con la pieza, y para fusionar también las capas entre sí; de esta manera evita que se descascaren o pelen durante la fase de cocción en el horno. Debido a la multiplicidad de pasos y períodos de secado, en un día no se puede terminar una tinaja. Durante los dos días en los que Zoraida se ocupó de esta pieza, empezó y terminó otras más: otra tinaja, una alcancía en forma de armadillo y una olla frijolera.

\section{Carlos elabora una réplica precolombina — renacimiento y extensión de la tradición}

Carlos desarrolló por su cuenta las técnicas para lograr un acabado similar al que muestran piezas muy elaboradas y decoradas de origen precolombino, en este caso para hacer una réplica de una vasija del tipo cerámico identificado como Jicote Polícromo, que data del período 800-1350 d.C., además de común y original 


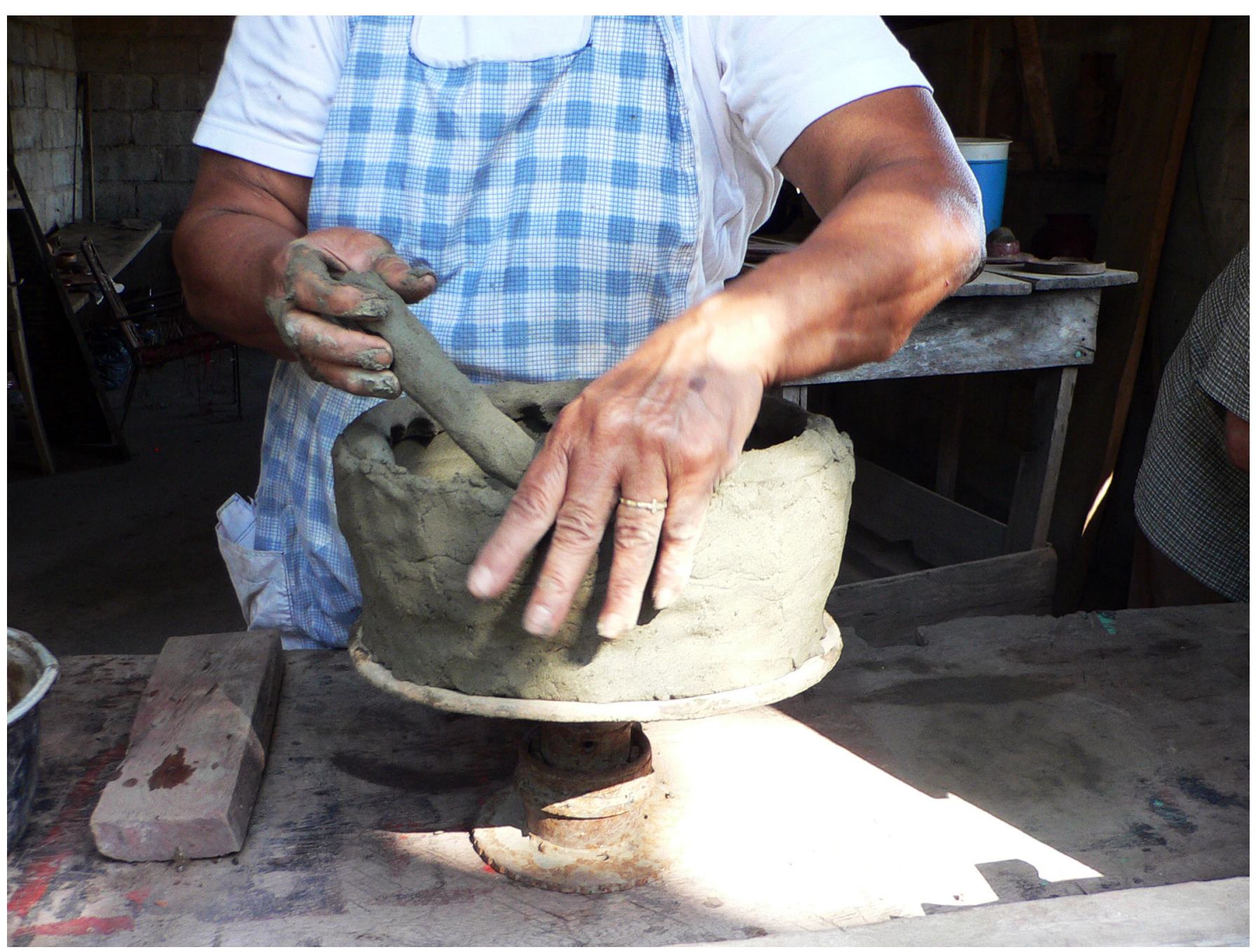

Figura 4: Zoraida coloca uno de los rollos en la tarea de levantar la tinaja (Foto A. Herrera).

del valle del Tempisque (Abel-Vidor et al., 1990). Aquí no se tratarán los pasos iniciales del proceso que comprenden la formación de una vasija esférica similares a los de la tinaja hecha por Zoraida. Se inicia cuando Carlos agrega pequeños pedazos de arcilla para modelar un rostro, manos y pies, imitando así los elementos encontrados en la vasija original. El paso siguiente es la pintura decorativa.

Como etapa preparativa, Carlos hace polvo los nódulos de pigmentos, saca las impuresas y mezcla con agua, para así lograr la pintura natural. Así se distingue a la tradición local de otras industrias contemporáneas de alfarería que emplean pinturas y esmaltes adquiridos comercialmente. Además de los tipos básicos de curiol -beige, rojo y también negro- puede combinar estos colores según la necesidad. Primero que nada aplica algunas capas de curiol con un pincel ancho. Antes de que se seque demasiado, frota este engobe 
para unirlo con la arcilla que está debajo, para que la pieza no se descascare. Carlos pinta los contornos del diseño antes de trazar líneas más prolijas (Figura 5), cubriendo las distintas áreas con color antes de agregar los detalles más delicados. Luego, pinta y pule de manera individual cada uno de los elementos decorativos y, finalmente, pule toda la pieza nuevamente, antes de colocarla en el horno.

Se debe hacer mención aparte de los dilemas de la situación del mercadeo de este tipo de piezas. Independientemente de la satisfacción que le da a Carlos hacer piezas complejas, con elementos añadidos que se elaboran de manera intrincada y/o con pintura extremadamente detallada, es difícil para él venderlas a un precio que le resulte redituable a la cantidad y a la calidad de horas de mano de obra que demandan. Carlos podría ganar más, poniendo un esfuerzo igual para producir un número mayor de piezas más sencillas y económicas, que la gran mayoría de los consumidores prefiere para sus compras.

Para evaluar la producción de alfarería decorada se deberían tomar en cuenta estas preferencias y su contextualización cultural. En la etapa antigua (prehispánica), dichas piezas fueron realizadas en grandes cantidades para su utilización en ceremonias religiosas, incluidas las funerarias; en los siglos siguientes desapareció su manufactura, para luego reaparecer durante el auge del turismo, en la segunda mitad del siglo veinte.

\section{Proyecciones: continuidades, discontinuidades e innovaciones}

Este apartado trata sobre ciertos rasgos materiales, organizacionales y estilísticos que muestran la persistencia y adaptabilidad de la tradición alfarera. Debido a que todas las observaciones y comentarios aparecen en la etapa presente (en este caso, la primera década del siglo XXI), se necesita inferir e interpretar la antigüedad de diferentes elementos de la cultura material y de las prácticas específicas. La colocación de cada uno en su propio contexto socio-temporal contribuye a un retrato dinámico de la industria alfarera. Esta sección sugiere cuáles ideas y prácticas han mantenido persumiblemente una continuidad desde la etapa antigua, cuáles aparecieron durante los siglos siguientes y cuáles surgieron en décadas recientes, según la información disponible. Para la etnografía, en colaboración con la historia, sería posible desarrollar explicaciones de las causas y los propósitos que produjeron el complejo cultural que existe hoy en día. Para la arqueología, la evidencia de una continuidad posibilita entendimientos de la cultura inmaterial o intangible de épocas pasadas para integrarla a los escasos vestigios físicos.

\section{Materias primas, herramientas y técnicas}

La alfarería empieza con la arcilla utilizada para plasmar las piezas. Hay minas dispersas a lo largo de la zona que comprende parte de los actuales distritos de Diriá y San Antonio donde ha persistido la tradición hasta hoy. Es cierto que, tarde o temprano, la arcilla de un lugar particular se agota; en consecuencia, surge una necesidad recurrente de buscar otras fuentes. En las últimas décadas, ha habido una lucha por asegurarse 


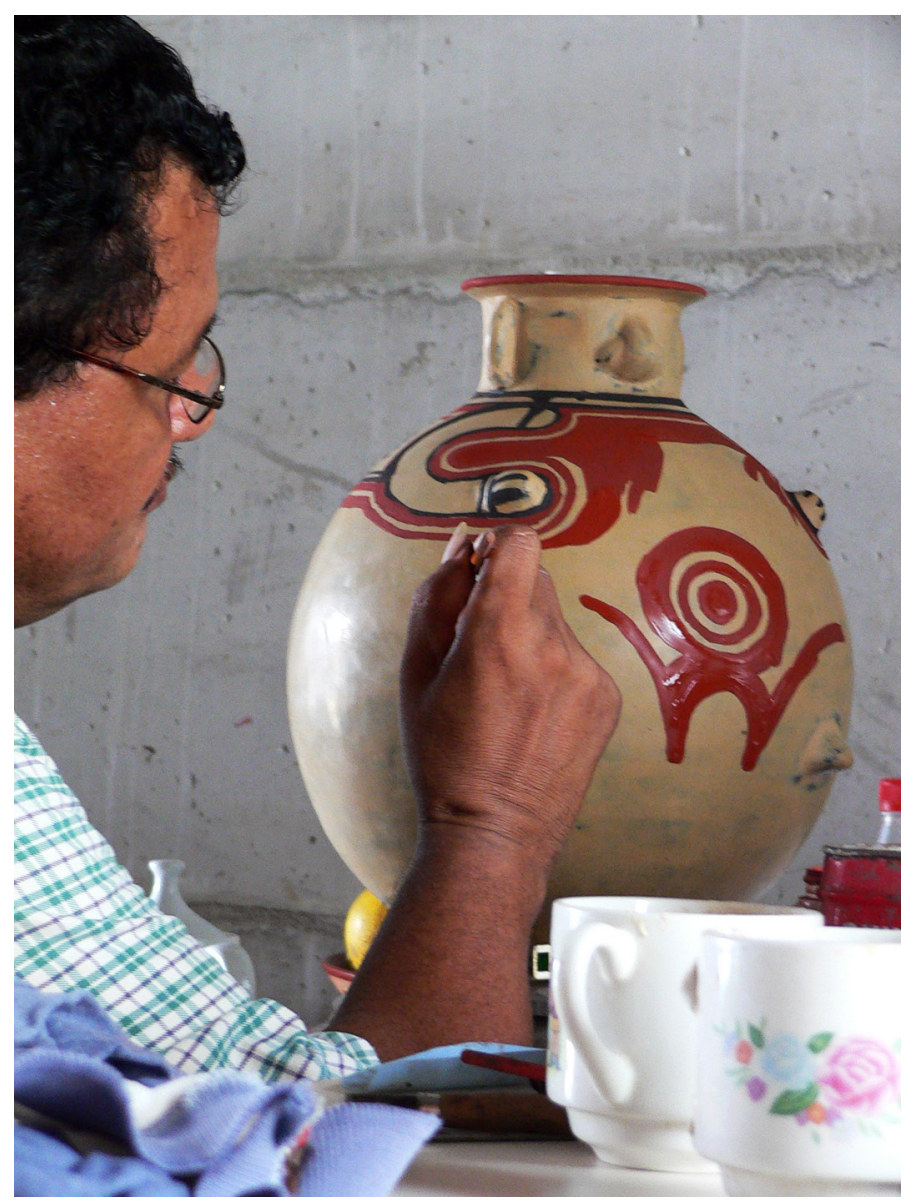

Figura 5: Carlos en la tarea de pintar el diseño usando el curiol diluido (Foto A. Herrera).

la provisión de este recurso para todos los artesanos (Weil, 2010), lo cual continúa en la actualidad en la conformación de un comité que apela al Estado costarricense para contar con una mina propia (Maribel Sánchez, comunicación personal, mayo de 2013).

Aparte de los depósitos de los curioles beige y rojo situados en los cerros detrás de San Vicente y Guaitil, no existen otras fuentes conocidas, excepto para el curiol negro que se consigue cerca de Santa Bárbara y otros lugares fuera de la zona. La presencia de este recurso en un lugar no muy accesible sugiere un conocimiento resguardado por medio de la tradición que podría remontarse a la época precolombina, dado su uso específico en una zona de producción alfarera durante esa época, como lo es el valle del río Tempisque. Si alguna vez se hubiera abandonado el uso del curiol, habría sido muy difícil localizar de nuevo los yacimientos dada su ubicación, el conocimiento implicado en la forma de obtención y preparación, así como su finalidad en el trabajo alfarero. Como parte de la tradición, se dice que si uno habla durante la búsqueda, los nódulos se esconden en el barro común porque son tímidos. A pesar de que la gente de hoy no permanece en silencio cuando realiza la búsqueda, esta creencia refuerza la inferencia de que es una tradición con raíces indígenas profundas al otorgarle al curiol una característica animada. 
Existe también una continuidad en las técnicas básicas de manufactura. El proceso continúa utilizando muchas de las herramientas tradicionales, así como los mismos movimientos. Es importante reconocer que la tradición no existe solamente en las formas de la cultura material, sino que además está literalmente "incorporada" de manera neuro-muscular en las personas que la transmiten de una generación a otra. Esto es notable al comparar la forma de trabajar y de emplear las herramientas de trabajo que se utilizan para levantar y adelgazar las paredes de un recipiente empleando un olote. La figura 6 muestra a la izquierda a Teodorica Villafuerte en 1949 (Stone, 1950, p. 274) y a la derecha a su sobrina Zoraida Grijalba en 2007.

Otro instrumento tradicional presentado antes, usado para "asentar" el barro y "alujar" las capas pintadas con curiol, es la piedra pulida y dura de cuarzo denominada sukia. Estas piedras proceden en su mayoría de tumbas precolombinas. Los arqueólogos han supuesto el uso de estas herramientas como pulidores de cerámica y, en efecto, algunos tiestos muestran las huellas de objetos lisos y duros en las superficies finamente pulidas de los recipientes (Herrera, 2001). Además, la arqueología también documenta huellas de olotes usados en los procesos iniciales del formado de las vasijas. Ambos hechos permiten reconocer el uso de estas mismas herramientas como parte del proceso de manufactura cerámica empleadas por los antiguos alfareros de Guanacaste.

Hoy, la mayoría de los artesanos prefiere utilizar herramientas hechas a partir de material plástico cuando se quiere pulir las piezas pintadas, ya que se disminuye el riesgo de dañarlas. De igual manera, en la segunda mitad del siglo veinte, los artesanos empezaron a emplear pinceles adquiridos en los centros comerciales urbanos en lugar de las plumas suaves del pecho de la gallina para pintar los detalles en las réplicas de antigüedades y en otras piezas con estilos nuevos de pintura, ya que se lograban acabados más finos.

Son varias las innovaciones recientes que se documentan a partir de la segunda mitad del siglo XX. Una de ellas es el uso de la tradicional máquina de moler maíz para moler los nódulos duros del curiol rojo, remplazando el uso del metate precolombino en esta función, del mismo modo que ocurrió con la molienda del maíz (Herrera, 2004; 2005) (Figura 7). Otra innovación es el rol, una plataforma girada por balines o cojinetes que se empuja a mano con la pieza colocada encima (Figura 7). El rol es muy práctico en los procesos de plasmar y pintar las vasijas redondas de acuerdo con su uso actual, lo cual produce preguntarse de qué manera lograban los artesanos ancestrales trazar líneas tan rectas sin tener nada abajo para girar la pieza, más allá de una base en forma de comal o quizá tan solo el uso de cuero, tejidos u hojas de vegetales. En los años ochenta, Karen Olsen de Figueres - esposa del expresidente José Figueres- consiguió los primeros roles de una empresa en los Estados Unidos (Weil, 2010). Actualmente, la mayoría de los talleres tienen roles de fabricación casera (talleres mecánicos de Santa Cruz) construidos con partes sacadas de autos y motocicletas viejas (Figura 8). 


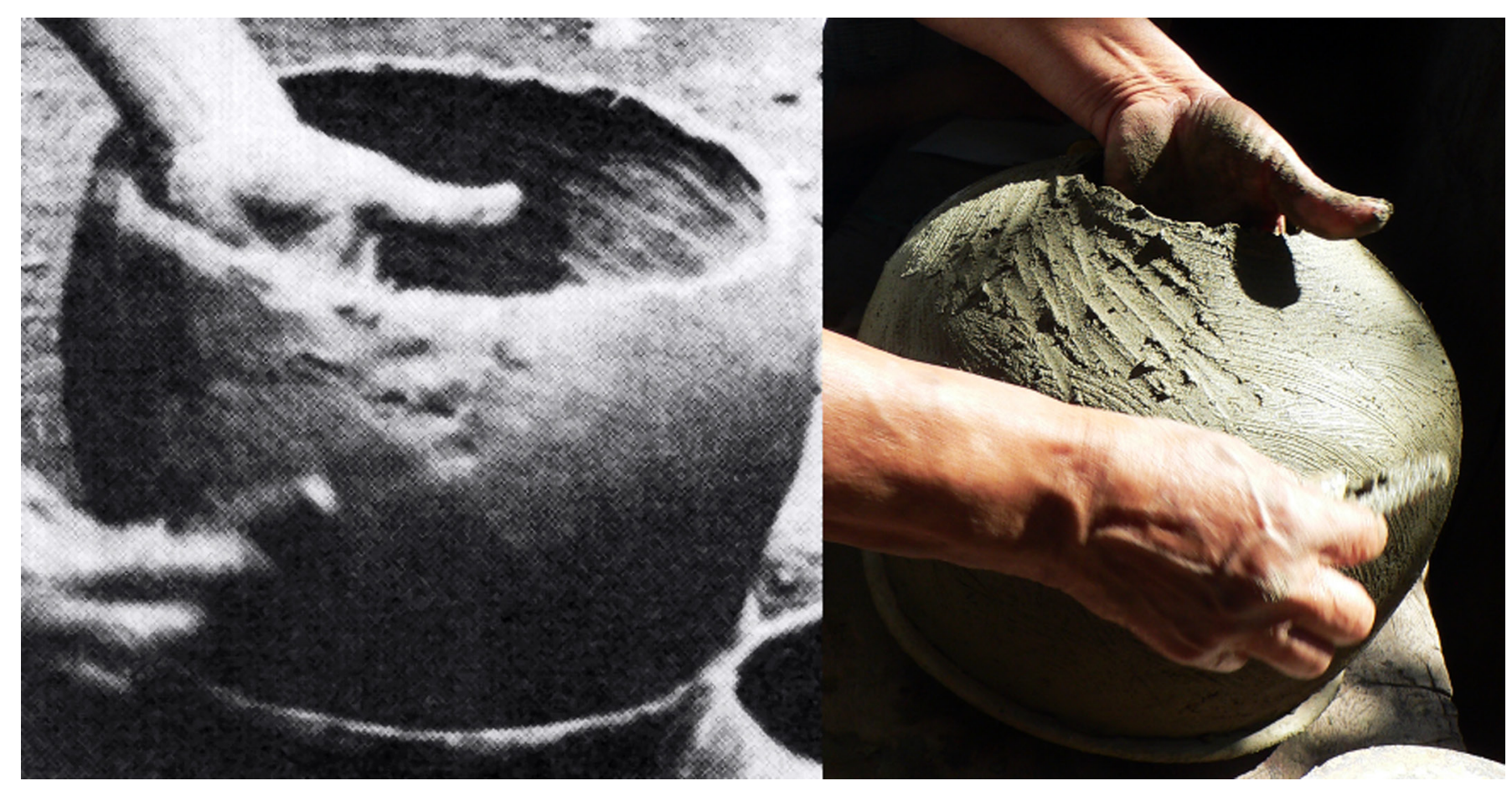

Figura 6: Continuidad en las técnicas de trabajo y la posición del cuerpo a través de las generaciones de artesanas (Foto D. Stone, A. Herrera).

\section{Organización social del trabajo}

La división del trabajo experimentó transformaciónes en lo que va de una generación a otra. Las diferencias entre personas de edad avanzada y lás más jovenes son tan relevantes como las diferencias entre géneros (Weil, 2006). Antes de la fundación de la primera cooperativa en 1967, las alfareras (todavía no había alfareros) casi siempre trabajaban solas, y lo hacían en el piso de tierra de sus casas, con la ayuda de sus familiares. Los hombres colaboraban para conseguir el barro común, el curiol, la arena y la leña, y a veces para hornear las piezas. Posteriormente, las llevaron al mercado en carretas tiradas por bueyes. Según la descripción de Doris Stone (2010 [1950]), el único aporte de mano de obra externa fue el de algunas "peonas" vecinas, que se les pagaba por el medio día y para realizar ciertas etapas del proceso.

Pese a que la mayoría seguía trabajando en sus casas, un grupo de artesanas organizadas en la cooperativa de mujeres siguieron produciendo utensilios de cocina, pero organizaron una división de tareas, según 


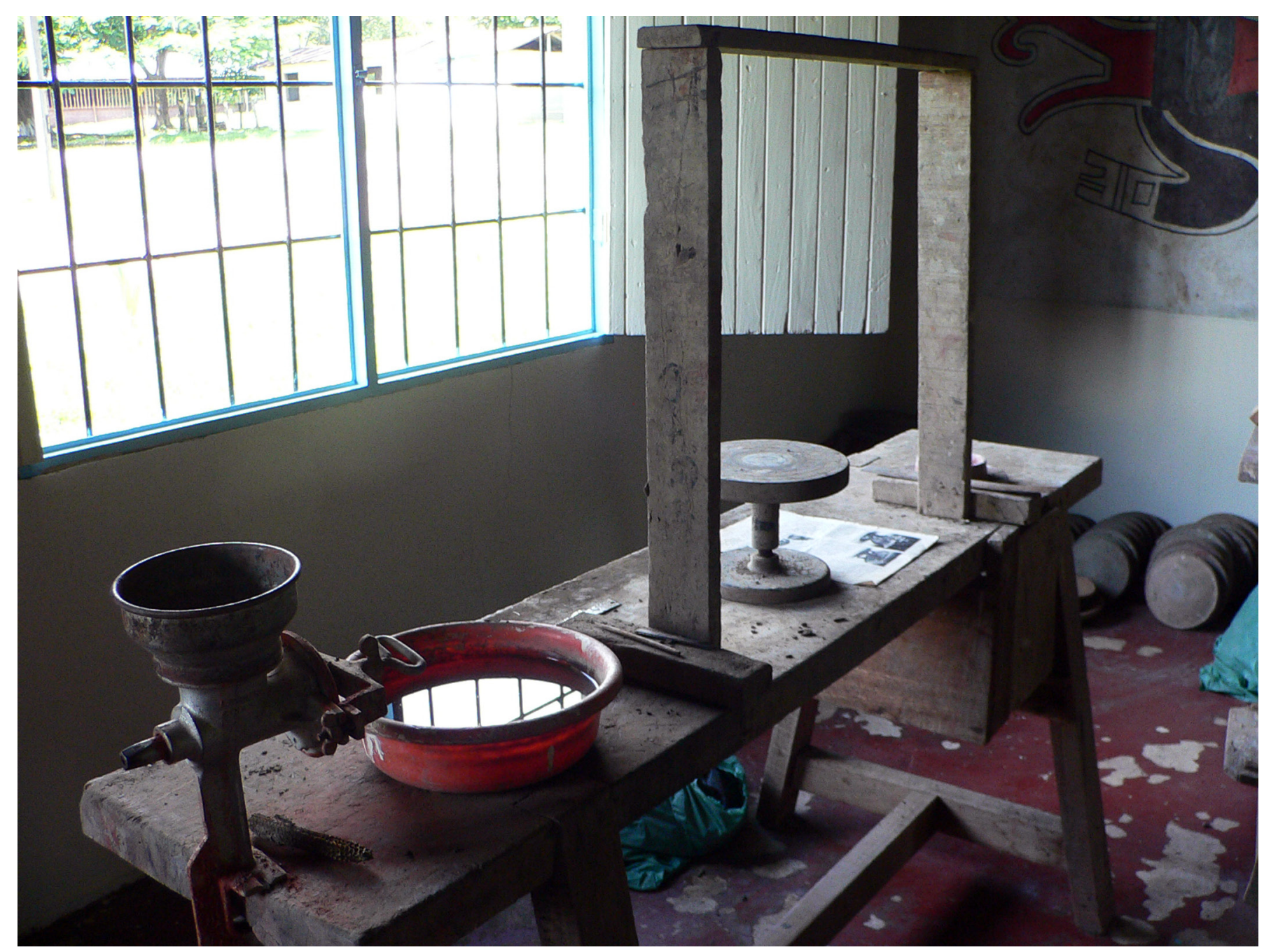

Figura 7: Mesa de trabajo con maquina de moler maíz empleada para moler curiol y rol introducido en 1984 (Foto A. Herrera).

las diferencias en sus destrezas y preferencias. Recibían sueldos, en lugar de ganancias directamente derivadas de las ventas particulares. A todo esto, por los consejos y recursos brindados por una serie de "agentes de cambio" del gobierno costarricense y de otros países, pudieron alcanzar otras destrezas y así responder mejor al nuevo mercado turístico. Algunas de las artesanas experimentaron con diferentes métodos y diseños (Shaw y Steinbauer, 1973; Maribel Sánchez, comunicación personal, mayo de 2013). Paulatinamente, aprendieron a reproducir los complejos acabados de origen precolombino y crearon piezas innovadoras (por ejemplo, soportes huecos hechos a partir de moldes).

Al mismo tiempo, algunos hombres comenzaron a dedicarse a elaborar piezas, además de compartir el redescubrimiento de las técnicas antiguas. Muchos de estos hombres de la zona habían sido huaqueros, y de esta manera adquirieron conocimientos sobre antigüedades, dando origen a su inspiración para hacer réplicas precolombinas. 


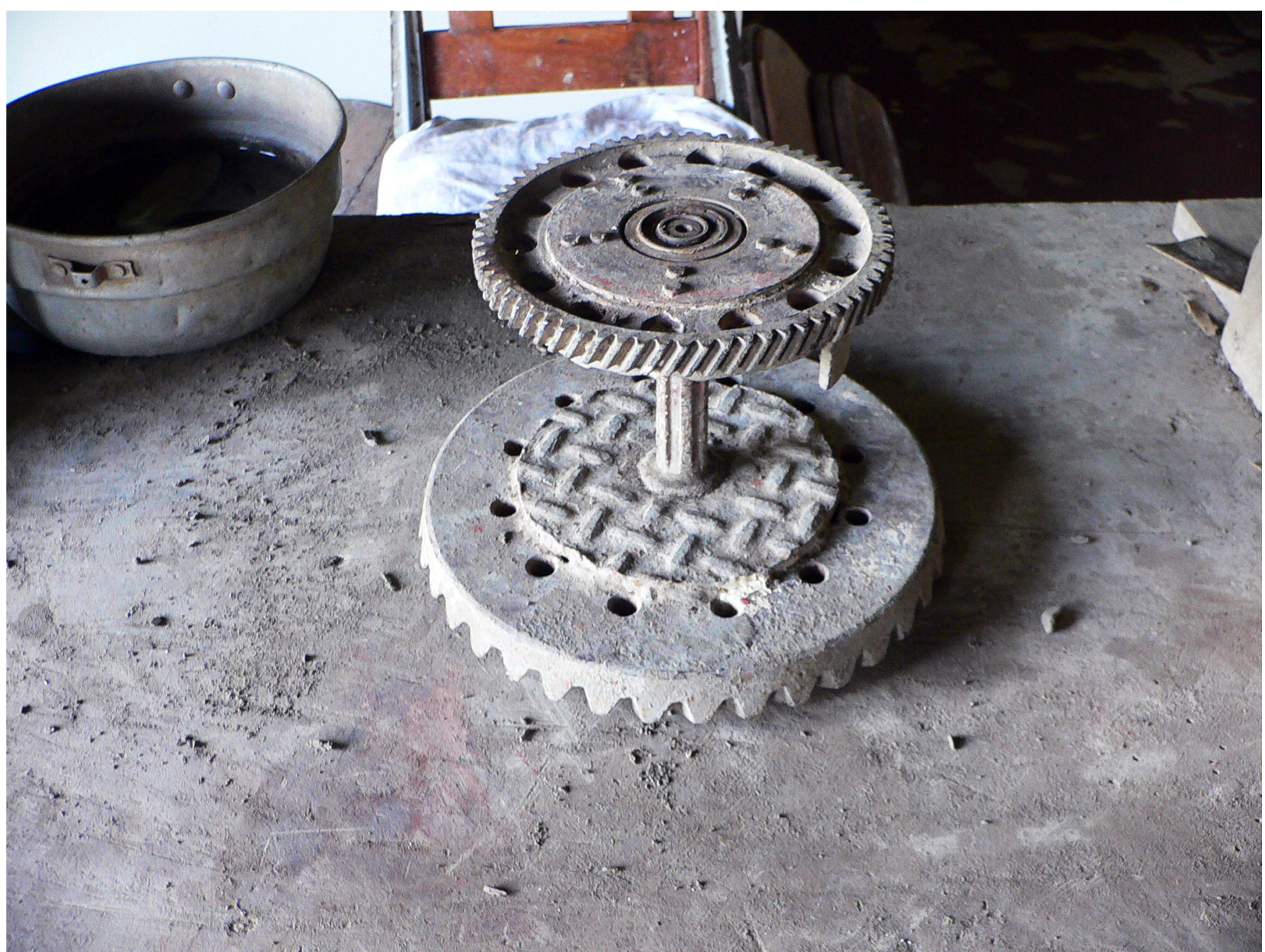

Figura 8: Rol de fabricación local (Foto A. Herrera).

El movimiento cooperativo reflejó la ética y política de los años sesenta y setenta, no solamente del gobierno social demócrata de Costa Rica, sino que también de otras naciones quienes apoyaron estas iniciativas. Sin embargo, cuando a partir de los años ochenta se aplicaron políticas neoliberales, las cooperativas fueron perdiendo el apoyo del exterior. No obstante, un grupo de hombres siguió una década más con su propia cooperativa, pero no las mujeres que regresaron a sus casas. Para las mujeres siempre había sido difícil ir a trabajar en un lugar centralizado, debido a las obligaciones del hogar. Tenían que cumplirlas temprano por la mañana antes de salir, y por la noche después de regresar (Weil, 2001). Muchas de estas mujeres aprovecharon sus experiencias del cooperativismo para establecer talleres cercanos a sus casas, con equipos modernos e integrando regularmente mano de obra de vecinos. Hoy, muchos de los talleres funcionan con diferentes especialistas, contratados para elaborar, pulir y decorar las piezas. Es diferente al negocio de comales de las socias Maira y Karen, que constituye un viejo modelo de trabajo entre parientes. 


\section{Diversificación estilística y experimentación}

Hortensia Briceño Villafuerte, directora de la primera cooperativa de mujeres, entre 1967 y 1983, es una de las pioneras que contribuyen con sus relatos respecto de las innovaciones que se operaron en la industria durante la segunda mitad del siglo veinte. Esta historia oral preserva los detalles de la transición al estilo que ahora se denomina como motivos chorotegas, que están inspirados por la artesanía precolombina (Herrera y Weil, 2009; Weil, 2010). La figura 9 revela los logros de los primeros años de rescate y renovación de la tradición por parte de doña Hortensia. La pieza no es tan fina, ni tan fiel a los motivos tradicionales de las réplicas más avanzadas realizadas a partir de los años noventa. Merece destacarse el reto que significó realizar las efigies de jaguares y otros animales en forma de vasija trípode que es emblemático de este estilo. De igual forma parte, las piernas y cabezas, dado que son huecas, explotan en el horno, si previamente no se incluyen pelotitas de barro para que absorban el exceso de calor, además de practicarle pequeñas ranuras que permiten un cocido uniforme.

De cualquier manera, debieron pasar muchos años hasta que los artesanos pudieran llegar a reproducir los intrincados acabados pintados precolombinos. Los pocos artistas con las destrezas requeridas para hacer este tipo de trabajos son bien remunerados porque son muy requeridos por ser especialistas. Van de un taller a otro, y son remunerados por cada pieza que pintan. Gracias a la práctica, aprendieron a hacer réplicas muy exactas, pero es más común que mezclen los motivos de diferentes prototipos, con algunas modificaciones originales.

La transformación del comal de utensilio doméstico a colgante es un buen ejemplo de los estilos híbridos que prevalecen actualmente. En lugar de la superficie lisa del comal, el colgante lleva una o más capas de engobe, y una multiplicidad de diseños grabados, pintados, o ambos, así como tamaños y formas. Es un adorno de fácil traslado, y por ello es común ver colgantes en las paredes de hogares, negocios y edificios públicos. De otras formas funcionales y uniformes, ya ha sido mencionada la tinaja. Hoy, se las encuentra tinajas de diversas alturas, de hasta más de un metro, y con accesorios tales como vertederos y argollas.

En los años noventa, surgió otro estilo que ahora caracteriza la mayor parte de la alfarería producida en la última década. Se denomina motivos ecológicos siguiendo las preferencias de los visitantes al país que aprecian la fauna y la flora iconográficas del ecoturismo. Se siguen representando felinos, reptiles y aves de la iconografía precolombina, además de tortugas, colibríes, mariposas y otros (Figura 10). En este estilo, las representaciones son más realistas que las figuras estilizadas y abstractas precolombinas, lo que permite el uso de otras técnicas de pintar y colores comerciales.

En términos generales, los cambios de estilo y de otros aspectos de la industria alfarera siguen un proceso dialéctico entre las ideas creativas de los productores y las preferencias de los consumidores (Weil, 2004). Lo que se vende bien se hace; lo que no se vende bien no se puede seguir produciendo. Es por eso que hay demasiados elementos por tomar en cuenta, como para suponer que los investigadores estén en condiciones de pronosticar con alguna certidumbre los rasgos futuros de la artesanía en esta zona. 


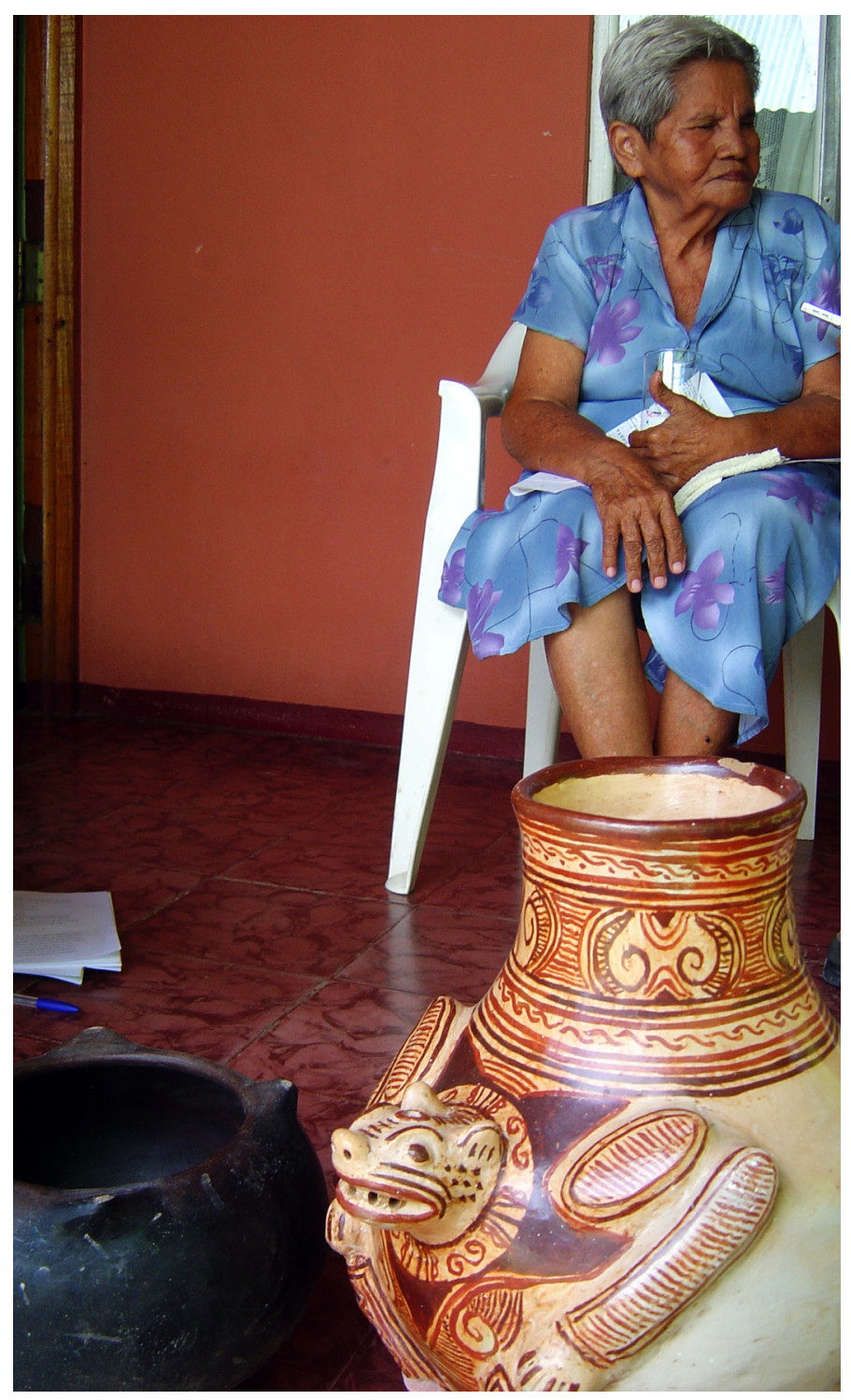

Figura 9: Hortensia Briceño muestra su pieza estilo chorotega elaborada cerca de 1980 (Foto A. Herrera).

\section{Implicaciones para las investigaciones futuras}

A pesar de que estas observaciones sobre la manufactura de alfarería representan un paso adelante, todavía queda mucho por aprender sobre la tradición alfarera que ha persistido en San Vicente y Guaitil. Además de los sitios precolombinos donde se han encontrado piezas con estilos sofisticados ampliamente conocidos -y sobre los cuales existen registros en el Museo Nacional de Costa Rica (MNCR, 1979)- es necesario continuar con las excavaciones en estos y otros sitios con la esperanza de recuperar restos de la vida cotidiana, entre los que se esperaría hallar espacios de trabajo alfarero. Así podremos reconocer aspectos de 


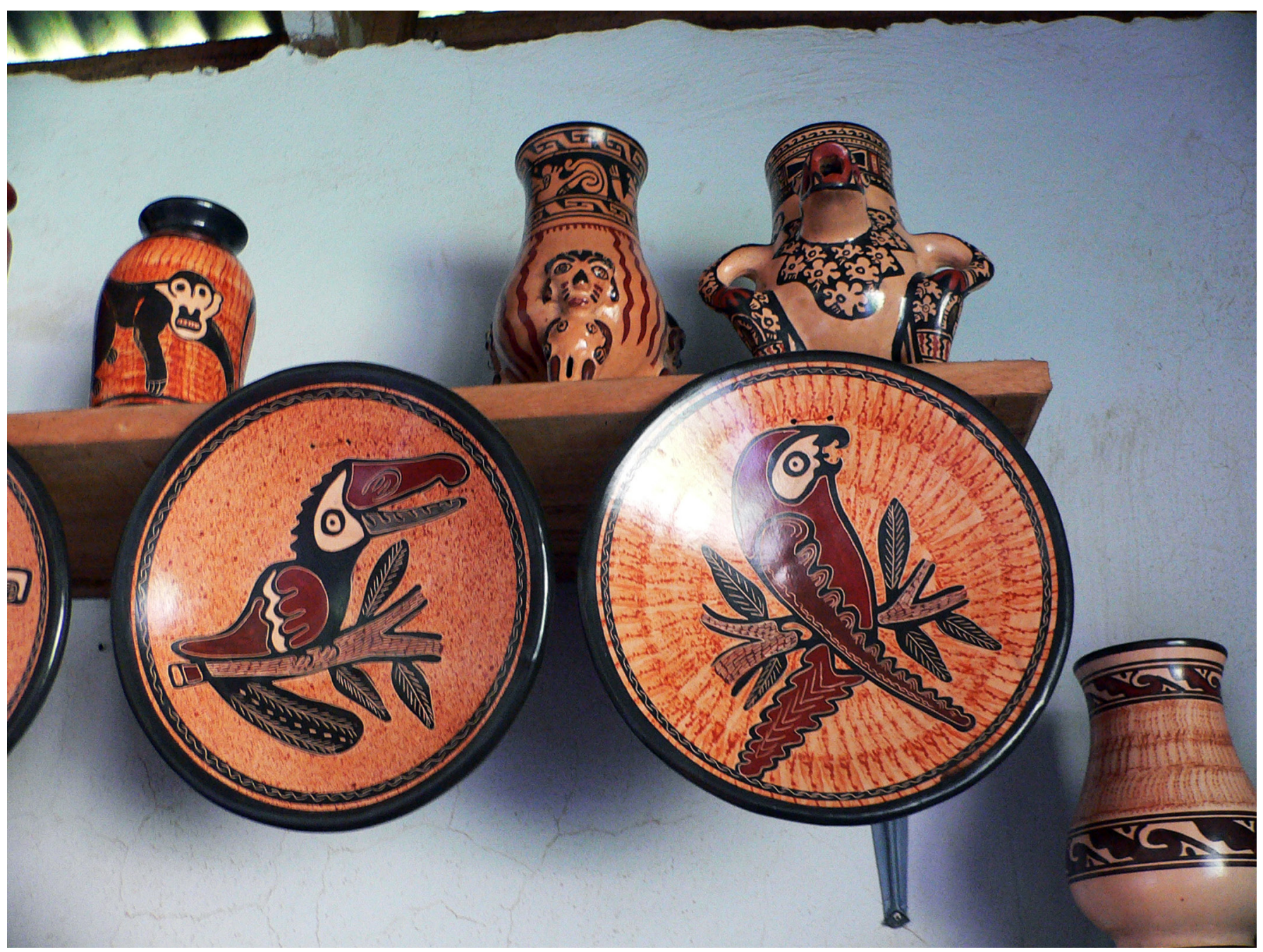

Figura 10: Colgantes con motivos ecológicos en exhibición para su venta (Foto A. Herrera).

la manufactura y su relación con la producción doméstica o especializada, de la cuales derivó la tradición actual. Los estudios sobre composición de pastas realizados a ciertos tipos cerámicos de la Gran Nicoya (Lange et al., 1990) resultaron en la definición de la procedencia geográfica de algunos de ellos, tal es el caso del tipo Jicote Policromo - con una amplia variedad de estilos- cuyo centro de manufactura se localiza en el valle del Tempisque, donde se sitúan San Vicente y Guaitil. Este tipo muestra, además, una estandarización en cuanto a la forma y diseños, lo cual está relacionado con el trabajo especializado, según Prudence Rice (1991). Esta autora además señala que la especialización debe buscarse en tres niveles: sitios, recursos y artesanos especializados. Si la zona de estudio cuenta con recursos especializados -en este caso curioles 
y fuentes de arcilla- entonces muy probablemente eso explica por qué persistió ahí la tradición. Podría ser, hipotéticamente, una de las zonas que albergaba artesanos especialistas, no solo para la creación de tipos como Jicote Policromo, sino otros más antiguos que muestran también diseños intrincados y estandarización productiva.

En esta misma línea será imprescindible hallar sitios que saquen a la luz vestigios que documentan las épocas que van desde la colonia española hasta la primera mitad del siglo veinte. Es muy probable que estos sitios se encuentren debajo de las casas actuales de los alrededores de Santa Bárbara, Guaitil, San Vicente y comunidades aledañas, debido a que si la tradición persistió desde las épocas precolombinas hasta la actualidad, debió hacerlo en los mismos lugares en que ocurren actualmente.

Lo más urgente sería el trabajo de campo con alfareras y alfareros mayores para la producción de archivos digitales que contengan la historia oral. Siempre quedan menos personas vivas con las experiencias personales que les posibilitan describir e interpretar las prácticas, conocimientos y creencias existentes durante la primera mitad del siglo XX. Entre ellas, hay muy pocas artesanas que han practicado la alfarería para ganarse la vida en esa época de una industria casera enfocado en cerámica culinaria. Además, es difícil encontrar mujeres y también hombres involucrados a partir de los años sesenta en el rescate de los estilos ceremoniales precolombinos. Hay pocos de esos pioneros que todavía elaboran piezas finas. El asunto no es solamente la edad avanzada de tales personas, sino también la competencia de souvenirs baratos en un mercado artesanal siempre más saturado. Entonces, más allá de la continuidad de la identidad cultural de la zona, se trata de refortalecer la economía local por medio de un turismo cultural con artesanías auténticas y de alta calidad. El aporte potencial de los trabajos de campo dependerá de la colaboración entre investigadores profesionales y la gente de las comunidades alfareras (Weil, 2010).

Para investigar a fondo la alfarería en la actualidad, será necesario recabar registros grabados de los artesanos por medio de vídeos que permitan reconocer mejor los detalles de los procesos de manufactura, especialmente cuando trabajan juntas dos o más personas. Además, de esa manera se pueden documentar las regularidades y variaciones, cuando un artesano hace el mismo tipo de pieza varias veces, o cuando son diferentes artesanos los que lo hacen. A la vez, se pueden integrar estas observaciones detalladas de los procesos de manufactura, con grabaciones de los comentarios de los mismos artesanos en relación con las técnicas y al significado de su trabajo; y siempre dirigido a un trabajo riguroso, comparativo y crítico.

Cabe enfatizar que contamos con los aportes invaluables de una serie de investigadores, empezando con la visita ya mencionada de Anastasio Alfaro, durante la segunda década del siglo veinte. Esta tradición merece un puesto destacado entre los casos clásicos de la alfarería latinoamericana y que demuestran la persistencia de la tradición desde tiempos precolombinos. 


\section{Agradecimientos}

Queremos agradecer profundamente a los artesanos Maira Grijalba, Karen Salinas, Zoraida Grijalba y Carlos Grijalba por demostrar su trabajo y compartir sus conocimientos, opiniones y reflexiones. También a Hortensia Briceño, Maribel Sánchez y Luciano Grijalba, quienes han contado sus experiencias. Todos ellos, así como las familias y vecinos de San Vicente y Guaitil, siempre han estado abiertos e integrarnos en su trabajo y vida cotidiana, por lo que apreciamos y reconocemos sus esfuerzos en mantener la tradición.

\section{Referencias bibliográficas}

Abel, S. (1978). An interpretation of two burnt clay features in an early lower central American village Vidor site, Bay of Culebra, Guanacaste (Tesis de maestría inédita). Brown University, Rhode Island.

Abel-Vidor, S. (1980). The historical sources for the Greater Nicoya archaeological sub-area. Vinculos, 6, 155-186.

Abel-Vidor, S., Baudez, C., Bishop, R., Bonilla, L., Calvo, M., Creamer, W., Day, J., Guerrero, J. V., Healy, P., Hoopes, J., Lange, F. W., Salgado, S., Strossner, R. y Tilet, A. (1990). Principales tipos cerámicos y variedades de la Gran Nicoya. Vinculos, 13(1-2), 35-317.

Alfaro, A. (1914). La cerámica de Chira. Pandemónium, 9, 689-691.

Constenla, A. (1994). Las lenguas de la Gran Nicoya. Vínculos, 18-19(1-2), 191-208.

Dobres, M.-A. (1999). Technology's links and chaînes: the processual unfolding of technique and the technician. En M.-A. Dobres y C. Hoffman (comps), The social dynamics of technology: Practice, politics and world views (pp. 124-146). Washington, D.C.: Smithsonian Institution Press.

Gould, S. J. (1988). Time's arrow, time's cycle: Myth and metaphor in the discovery of geological time. Cambridge: Harvard University Press.

Herrera, A. (2001). Tecnología alfarera de grupos ribereños de la cuenca del Golfo de Nicoya durante los períodos Bagaces (300-800d.C.) y Sapoá (800-1350 d.C.) (Tesis de licenciatura inédita). Universidad de Costa Rica, San José, Costa Rica.

Herrera, A. (2004). La tortilla nuestra de cada día, dánosla hoy y perdona nuestras omisiones. En M. del C. Araya y M. Bolaños (comps.), Retos y perspectivas de la antropología social y la arqueología en Costa Rica a principios del siglo XXI (pp. 43-51). San José: Editorial de la Universidad de Costa Rica.

Herrera, A. (2005). Al reencuentro de los ancestros: Mwaing Daamalut: Kokapoijmi. Lourdes Monte de Oca: Editorial ICER.

Herrera, A. y Weil, J. (2009). Tradición y cambio en la cerámica producida en las comunidades de San Vi- 
cente y Guaitil. Aporte al Proyecto Denominación de origen para la cerámica Chorotega (manuscrito inédito). FUNDAUNA, Heredia.

Lange, F. (1984). The Greater Nicoya archaeological subarea. En F. Lange y D. Stone (eds), The archaeology of Lower Central America (pp. 165-194). SAR Press: Alburquerque, New Mexico.

Lange, F., Bishop, R. y Lange, P. (1990). La geología y arqueología de la cerámica prehistórica de la Gran Nicoya. Vínculos, 13, 7-34.

Meléndez, C. (1974). Viajeros por Guanacaste. San José: Ministerio de Cultura, Juventud y Deportes.

Museo Nacional de Costa Rica (MNCR) (1979). San Vicente (manuscrito inédito). Departamento de Antropología y Historia, Museo Nacional de Costa Rica. San José.

Ortner, S. (2006). Anthropology and social theory: Culture, power, and the acting subject. Durham, NC: Duke University Press.

Rice, P. (1991). Specialization, standardization, and diversity: a retrospective. En F. Lange y R. Bishop (eds), The ceramic legacy of Anna Sheppard (pp. 257-279). Niwot: The University Press of Colorado.

Shaw, S. y Steinbauer, M. (1973). Pottery making in rural Costa Rica (manuscrito inédito). San José: Central American Field Program, Associated Colleges of the Midwest.

Solís, F. (1996). Asentamientos y costumbres funararias en la zona Cañas-Liberia durante el Período Bagaces (300-800 d.C.) (Tesis de licenciatura inédita). Universidad de Costa Rica, San José, Costa Rica.

Solórzano, J. C. y Quirós, C. (2006). Costa Rica en el Siglo XVI: Descubrimiento, exploración y conquista. San José: Editorial Universidad de Costa Rica.

Stone, D. (2010). Notes on present-day pottery making and its economy in the ancient Chorotegan area. Vinculos, 33(1-2), 137-148 [El artículo original de 1950 apareció en Middle America Research Records, 1(16), 269-280].

Wagner, P. (1974). Nicoya: una geografía cultural. Anne Langerak Pater, traductora. Revista de la Universidad de Costa Rica, 3, 163-221 [Nicoya: A Cultural Geography, el artículo original de 1958 aparació en University of California Publications in Geography, 12(3), 195-250].

Weil, J. (2001). Un ecomuseo para San Vicente: artesanos de cerámica y turismo cultural en Costa Rica. Herencia, 13(1), 137-154.

Weil, J. (2004). Virtual antiquities, consumption values, and the cultural heritage economy in a Costa Rican artisan community. En C. Werner y D. Bell (comps.), Values and Valuables: From the sacred to the symbolic (pp. 231-256). Walnut Creek, California: AltaMira Press.

Weil, J. (2006). Hacia un modelo del cambio de roles sociales en una industria casera de cerámica en San Vicente de Nicoya. Vínculos, 29(1-2), 61-75.

Weil, J. (2010). Cambios y continuidades en una industria alfarera de la Península de Nicoya desde mediados del siglo veinte. Vínculos, 33(1-2), 105-135. 